\title{
Evidence for Regional Catecholamine Uptake and Storage Sites in the Transplanted Human Heart by Positron Emission Tomography
}

\author{
Markus Schwaiger, Gary D. Hutchins, Victor Kaiff, Karen Rosenspire, Michael S. Haka, \\ Shirley Mallette, G. Michael Deeb, ${ }^{\star}$ Gerald D. Abrams, ${ }^{\star}$ and Donald Wieland \\ Department of Internal Medicine, Division of Nuclear Medicine; *Department of Thoracic Surgery; and \\ ${ }^{\ddagger}$ Department of Pathology, University of Michigan Medical Center, Ann Arbor, Michigan 48109-0028
}

\begin{abstract}
Positron emission tomography in combination with the newly introduced catecholamine analogue $\left[{ }^{11} \mathrm{C}\right]$ hydroxyephedrine ( $\left.{ }^{11} \mathrm{C}\right]$ HED) enables the noninvasive delineation of sympathetic nerve terminals of the heart. To address the ongoing controversy over possible reinnervation of the human transplant, 5 healthy control subjects and 11 patients were studied after cardiac transplant by this imaging approach. Regional $\left[{ }^{11}\right.$ C]HED retention was compared to regional blood flow as assessed by rubidium-82. Transplant patients were divided into two groups. Group I had recent ( $<1 \mathrm{yr}, 4.4 \pm 2.3 \mathrm{mo}$ ) surgery, while group II patients underwent cardiac transplantation more than 2 yr before imaging (3.5 $\pm 1.3 \mathrm{yr}) \cdot\left[{ }^{11} \mathrm{C}\right] \mathrm{HED}$ retention paralleled blood flow in normals, but was homogeneously reduced in group $I$. In contrast, group II patients revealed heterogeneous [ $\left.{ }^{11} \mathrm{C}\right]$ HED retention, with increased uptake in the proximal anterior and septal wall. Quantitative evaluation of $\left[{ }^{11} \mathrm{C}\right] \mathrm{HED}$ retention revealed a $70 \%$ reduction in group I and $59 \%$ reduction in group II patients $(P<0.001)$. In group II patients, [ $\left.{ }^{11} \mathrm{C}\right]$ HED retention reached $60 \%$ of normal in the proximal anterior wall. These data suggest the presence of neuronal tissue in the transplanted human heart, which may reflect regional sympathetic reinnervation. (J. Clin. Invest. 1991. 87:1681-1690.) Key words: cardiac transplantation • reinnervation • carbon-11 hydroxyephedrine $\bullet$ positron emission tomography
\end{abstract}

\section{Introduction}

Cardiac transplantation is now an accepted treatment for end stage cardiac disease. Survival rates of $>75 \%$ have been reported for the first $5 \mathrm{yr}$ after the operation (1). However, physical performance remains impaired in most patients after the transplant procedure (2). This deficient physical recovery may be partly explained by denervation of the donor heart. Heart rate response to exercise is attenuated due to the absence of atrial innervation (3). The necessary increase in cardiac output during increased physical activity is achieved primarily through an increase of stroke volume (4). Increases in left ventricular end-diastolic pressure and internal diameter suggest that increased myocardial fiber length is responsible for the

Address reprint requests to Dr. Markus Schwaiger, University of Michigan Medical Center, 1500 E. Medical Center Drive, UH B1 G505, Box 0028, Ann Arbor, MI 48109-0028.

Received for publication 26 June 1990 and in revised form 6 December 1990 .

J. Clin. Invest.

(c) The American Society for Clinical Investigation, Inc.

$0021-9738 / 91 / 05 / 1681 / 10 \$ 2.00$

Volume 87, May 1991, 1681-1690 increased stroke volume in the denervated heart $(5,6)$. However, there is evidence that the response of heart rate to exercise improves over time in patients with cardiac transplantation (7). Although this functional improvement is thought to reflect adaptation and/or increased sensitivity of the sinus node to circulating catecholamines, it may be due to reinnervation of the donor heart (8-11).

Reinnervation of transplanted hearts in animals occurs during the first 9-12 mo after surgery $(10,12-14)$. However, data demonstrating reinnervation of the human transplanted heart are scarce $(10,12)$. This paucity of data is a direct result of insufficient techniques for the accurate in vivo evaluation of the autonomic nervous system of the human heart. With the advent of imaging methods that enable the delineation of the sympathetic nerve terminals, the noninvasive assessment of the integrity of the sympathetic nervous system has become possible (15-17). The guanethidine analogue, ${ }^{123}$ I-meta-iodobenzylguanidine (MIBG) has been employed in combination with conventional nuclear medicine techniques to characterize the effect of various cardiac diseases on the sympathetic nervous system. Radionuclide distribution images of MIBG have demonstrated alterations of the sympathetic nervous system in patients with ischemic heart disease and cardiomyopathy (1719). More recently $\left[{ }^{11} \mathrm{C}\right]$ hydroxyephedrine $\left(\left[{ }^{11} \mathrm{C}\right] \mathrm{HED}\right)^{1}$ has been introduced as a positron-emitting radiopharmaceutical that traces the uptake and storage of norepinephrine in the presynaptic adrenergic nerve terminal $(16,20)$. In combination with positron emission tomography (PET), this approach enables the quantitative assessment of regional neuronal tracer retention in the heart (20). Animal studies have shown that regional denervation of the canine heart leads to markedly reduced retention of this tracer while perfusion is preserved, demonstrating the specificity of sympathetic hydroxyephedrine uptake (15). Tracer kinetic modeling is being developed to quantify the regional catecholamine storage capacity of heart tissue (21). Using this approach a linear relationship between the calculated catecholamine storage capacity and measured tissue norepinephrine content has been demonstrated in animals (22)

The purpose of this study was to use this new imaging approach to investigate possible reinnervation of the human transplanted heart. Dynamic PET imaging was employed in normal control subjects as well as in patients with recent and remote cardiac transplantation. Regional $\left[{ }^{11} \mathrm{C}\right]$ HED retention fractions were compared between each of those groups to assess the integrity of the sympathetic nervous system of transplanted hearts. Myocardial blood flow was assessed using infusion of rubidium- 82 to examine the integrity of the myocardium.

1. Abbreviations used in this paper: $\left[{ }^{11} \mathrm{C}\right] \mathrm{HED},\left[{ }^{11} \mathrm{C}\right] \mathrm{hydroxyephedrine;}$ PET, positive emission tomography; ROI, region of interest. 


\section{Methods}

\section{Patient selection}

Control group. Five normal healthy male volunteers were selected. These individuals had no history or clinical evidence of any disease that may affect the cardiovascular system. These subjects did not take any medications at the time of the study.

Patient population. Patients with cardiac transplants were selected from the University of Michigan Cardiac Transplant Program. Two groups of patients were studied. Group I consisted of five patients who were studied within the first year after transplant surgery $(4.4 \pm 2.3 \mathrm{mo})$. In contrast, six group II patients had undergone cardiac transplantation more than $2 \mathrm{yr}$ before the imaging procedure $(42 \pm 22 \mathrm{mo})$. Patients were only included if there was no clinical evidence of cardiac rejection by biopsy and other noninvasive parameters at the time of the study. All patients received standard immunosuppressive therapy consisting of cyclosporine, immuran, and prednisone. Patients receiving any medication known to interfere with catecholamine uptake in presynaptic nerve terminals were excluded from this study (i.e., amiodarone or clonidine).

All patients and volunteers signed an informed consent form approved by the committee for clinical research at the University of Michigan.

\section{Synthesis of $\left[{ }^{11} C\right]$ hydroxyephedrine}

[ $\left.{ }^{11} \mathrm{C}\right] \mathrm{HED}$ was synthesized by the direct $\mathrm{N}$-methylation of the free base

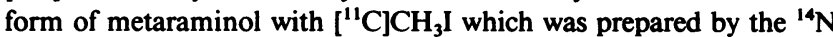
$(p, \alpha){ }^{11} \mathrm{C}$ reaction. Purification of $\left[{ }^{11} \mathrm{C}\right] \mathrm{HED}$ was accomplished by radio-HPLC using a $\mathrm{C}-18$ reverse-phase column. The column was eluted with $0.24 \mathrm{M}$ sodium phosphate at $4 \mathrm{ml} / \mathrm{min}$ for the first $10 \mathrm{~min}$ and then with $10 \%$ ethanol in $0.24 \mathrm{M}$ sodium phosphate at $3.5 \mathrm{ml} / \mathrm{min}$ for 10-20 min. The product peak was passed through an in-line 0.22- $\mu \mathrm{m}$ sterile filter into a sterile vial for subsequent direct intravenous injection. UV absorbance of a known amount of radioactivity was used to calculate the end-of-synthesis specific activity $(900 \pm 487 \mathrm{Ci} / \mathrm{mmol})$. Chemical and radiochemical purities were $>95 \%$. A more detailed description of the synthesis of [ $\left.{ }^{11} \mathrm{C}\right] \mathrm{HED}$ can be found elsewhere (16).

\section{Positron emission tomography}

All subjects were studied in a fasted state. The normal subjects and patients were imaged using the University of Michigan whole body scanners (931; Siemens, Hoffman Estates, IL/CTI, Knoxville, TN) which allow simultaneous imaging of 15 transaxial slices $(6.7-\mathrm{mm}$ slice thickness). Transmission scans were obtained with a retractable germanium-68 ring source and used for subsequent attenuation correction. $60 \mathrm{mCi}$ of rubidium-82 was injected using a strontium/rubidium generator (Squibb Diagnostics, New Brunswick, NJ) and a dedicated infusion system (Siemens/CTI) for the evaluation of regional myocardial blood flow. $60 \mathrm{~s}$ after the end of rubidium-82 infusion, PET images were acquired for $7 \mathrm{~min}$. A delay of $10 \mathrm{~min}$ was allowed after the acquisition of the blood flow images for physical decay of rubidium-82 $\left(t_{\gamma_{2}} 76 \mathrm{~s}\right)$. Subsequently, $20 \mathrm{mCi}$ of $\left[{ }^{11} \mathrm{C}\right]$ HED was injected as a slow bolus over $30 \mathrm{~s}$. Dynamic PET image acquisition was started simultaneously for $60 \mathrm{~min}$. The scanning protocol consisted of 15 images $(6$ $\times 30$-s images, $2 \times 60$-s images, $2 \times 150$-s images, $2 \times 300$-s images, 2 $\times 600$-s images, and $1 \times 1,200$-s image). The electrocardiogram was monitored continuously. Heart rate and blood pressure were measured before ["C]HED injection and every $2 \mathrm{~min}$ for $10 \mathrm{~min}$ after the injection.

\section{Data analysis}

After data acquisition, the sinogram data were corrected for attenuation and reconstructed using a conventional filtered back projection algorithm. A Hanning filter with a cutoff frequency of $1.12 \mathrm{cycles} / \mathrm{cm}$ was used producing images with a resolution of $9-10 \mathrm{~mm}$ full width half maximum. Using a SUN 4/110 workstation, the images were realigned perpendicular to the long axis of the left ventricle yielding 10 12 short axis views of myocardial tracer distribution extending from the apex to the base of the left ventricle (Fig. 1). Myocardial regions of interest (ROI) were defined on three of the short axis views representing base, midplane, and apex of the left ventricle. Two circular ROI's were defined to identify inner and outer myocardial boundaries. The ROI algorithm then divided the myocardial region into four sectors corresponding to anterior, lateral, inferior, and septal segments of the left ventricle. An additional ROI was placed manually over the left ventricular chamber for determination of arterial blood [ $\left.{ }^{11} \mathrm{C}\right]$ HED concentrations. Each of these defined ROI's were propagated over the entire sequence of temporal data and time-activity curves for both myocardial tissue and blood were generated. Because of the diminished $\left[{ }^{11} \mathrm{C}\right]-$ HED retention in the transplant patients, the myocardial regions were defined on the rubidium-82 images and copied to all $\left[{ }^{11} \mathrm{C}\right]$ HED images.

The retention fraction of $\left[{ }^{11} \mathrm{C}\right] \mathrm{HED}$ was calculated for each ROI by dividing the tissue carbon- 11 concentration at $60 \mathrm{~min}$ by the integral of the [ $\left.{ }^{1} \mathrm{C}\right] \mathrm{HED}$ concentration in the arterial blood from the time of injection to the end of the last scan $(60 \mathrm{~min})$. These retention fractions were then multiplied by 100 and expressed as percentage retention of the radiopharmaceutical.

Group data are expressed as the mean and standard deviation. The differences between the three patient groups were assessed using the unpaired $t$ test. A $P$ value of $<0.05$ was considered statistically significant.

\section{Clinical evaluation of the autonomic nervous system}

In addition to PET imaging, three patients with recent cardiac transplantation (group I) and four with remote cardiac transplantation (group II) underwent a clinical evaluation of the autonomic nervous system. The detailed aspects of this evaluation are outlined elsewhere (23). In brief, this examination included five tests measuring the heart rate and blood pressure response to various interventions. The heart rate changes were assessed in response to Valsalva maneuver, standing up (30:15 ratio) and deep breathing (maximum-minimum heart rate). The blood pressure was measured as a response to standing (postural blood pressure change) and sustained handgrip. These tests have been used and validated previously for the assessment of autonomic neuropathy in patients with diabetes mellitus (23).

\section{Histological analysis}

One patient in group II died 3 mo after the PET study (60 mo after transplantation). An autopsy was performed and histologic sections of the heart obtained. Blocks of tissue were taken from the anterior left ventricle at intervals from the base of the heart to the apex. Sections of formalin-fixed, paraffin-embedded tissue were stained with hematoxy-

Figure 1 (top). [" $\mathrm{C}] \mathrm{HED}$ and rubidium-82 images obtained in the normal volunteer. Eight short axis images through the left ventricle from apex (left upper row) to base (right lower row) are shown. The rubidium-82 images above (flow) indicate homogeneous uptake of the tracer through the left ventricle consistent with homogeneous myocardial blood flow. The [ $\left.{ }^{11} \mathrm{C}\right] \mathrm{HED}$ images below in corresponding planes indicate homogeneous tracer retention with high contrast between myocardial activity, lung activity, and blood activity. These images were obtained 30 min after intravenous injection of $\left[{ }^{11} \mathrm{C}\right] \mathrm{HED}$.

Figure 2 (bottom). Eight short axis PET images obtained in a patient with recent cardiac transplant ( 3 mo after cardiac transplantation). The circulation is identical as in Fig. 1. The blood flow images (above) show homogeneous blood flow throughout the left ventricle, while the $\left[{ }^{11} \mathrm{C}\right]-$ HED images below indicate marked reduction of tracer retention that is homogeneous throughout the left ventricle. 


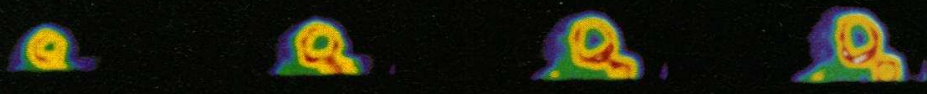

C-11 HED

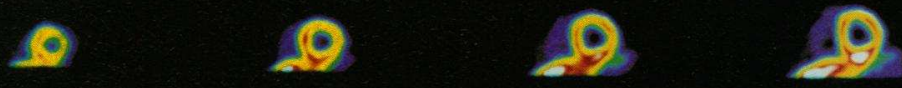

FLOY
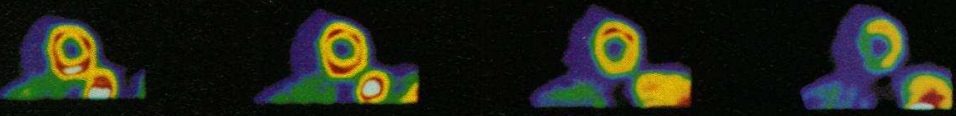

C-11 HED
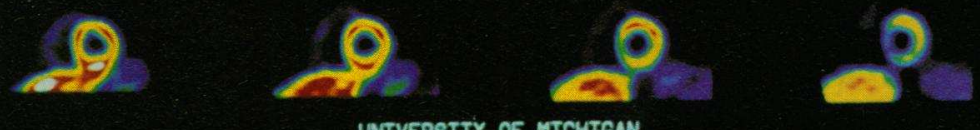

UNTVERSITY OF MICHICAN

(2127221)

FLo
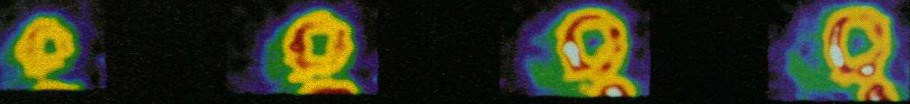

C-11 VED
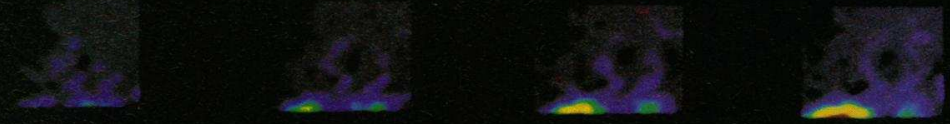

Fov
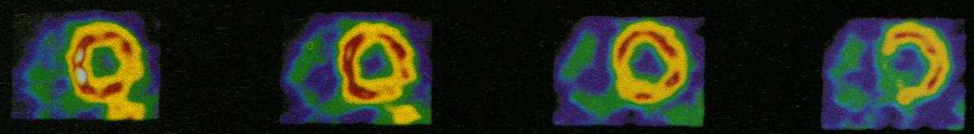

C-11 KED
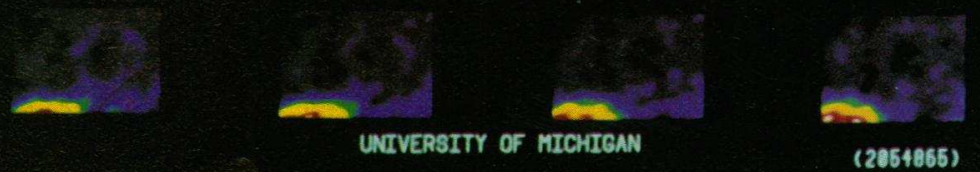
Table I. Hemodynamic Data

\begin{tabular}{lccc}
\hline & Normals & Eary transplants & Late transplants \\
\hline & $n=5$ & $n=5$ & $n=6$ \\
Baseline & & & \\
HR & $55 \pm 9$ & $94 \pm 10$ & $89 \pm 10$ \\
BP (s) & $116 \pm 8$ & $137 \pm 7^{*}$ & $128 \pm 16^{*}$ \\
$\quad(d)$ & $79 \pm 1$ & $94 \pm 7$ & $91 \pm 11$ \\
2 min after injections & & & \\
HR & $53 \pm 4$ & $88 \pm 5$ & $87 \pm 9$ \\
BP (s) & $117 \pm 7$ & $140 \pm 15^{*}$ & $137 \pm 23^{*}$ \\
$\quad(d)$ & $74 \pm 8$ & $95 \pm 9$ & $100 \pm 12$ \\
10 min after injection & & & $88 \pm 9$ \\
HR & $56 \pm 3$ & $89 \pm 5$ & $139 \pm 27^{*}$ \\
BP (s) & $117 \pm 8$ & $140 \pm 16^{*}$ & $101 \pm 12$ \\
(d) & $75 \pm 9$ & $95 \pm 12$ & \\
\hline
\end{tabular}

${ }^{*} P<0.05$ vs. normals.

lin and eosin, with the Holmes stain to demonstrate axons (24), and with an immunoperoxidase stain for S-100 to demonstrate intramyocardial nerves (25).

\section{Results}

Hemodynamic data. All individuals tolerated the injection of $\left[{ }^{11} \mathrm{C}\right] \mathrm{HED}$ without any side effects. Blood pressure and heart rate data for all three patient groups before and after the injection of $\left[{ }^{11} \mathrm{C}\right] \mathrm{HED}$ are displayed in Table $\mathrm{I}$. As expected, blood pressure was significantly higher in the patients with cardiac transplant than in the normal volunteers. However, there was not a significant difference between the hemodynamic data in patients with early and late cardiac transplantation. There was not a significant change in blood pressure or heart rate following the injection of $\left[{ }^{11} \mathrm{C}\right] \mathrm{HED}$ in all three groups.

Scintigraphic results. Fig. 1 shows blood flow and $\left[{ }^{11} \mathrm{C}\right]-$ HED images obtained in a volunteer. Homogeneous myocardial blood flow as shown on the rubidium-82 images was paralleled by homogeneous uptake of $\left[{ }^{11} \mathrm{C}\right] \mathrm{HED}$ throughout the entire left ventricle. Figs. 2 and 3 show examples of group I and group II patients. Regional myocardial blood flow as assessed by rubidium- 82 was homogeneous in both examples indicating the integrity of left ventricular myocardium. The corresponding $\left[{ }^{11} \mathrm{C}\right] \mathrm{HED}$ images, however, were markedly different from control. In the group I patient who underwent the cardiac transplantation 3 mo before the PET study, myocardial retention of $\left[{ }^{11} \mathrm{C}\right] \mathrm{HED}$ was homogeneously reduced. In the group II patient who was studied 55 mo after cardiac transplantation, there was considerable tracer retention in the anterior septal and anterior basal part of the left ventricle. In contrast, tracer retention in the apical and inferior wall were reduced to a similar degree as in the shown group I patient (Fig. 5).

Table II summarizes the results of $\left[{ }^{11} \mathrm{C}\right] \mathrm{HED}$ kinetics in all three patient groups. The myocardial retention of $\left[{ }^{11} \mathrm{C}\right] \mathrm{HED}$

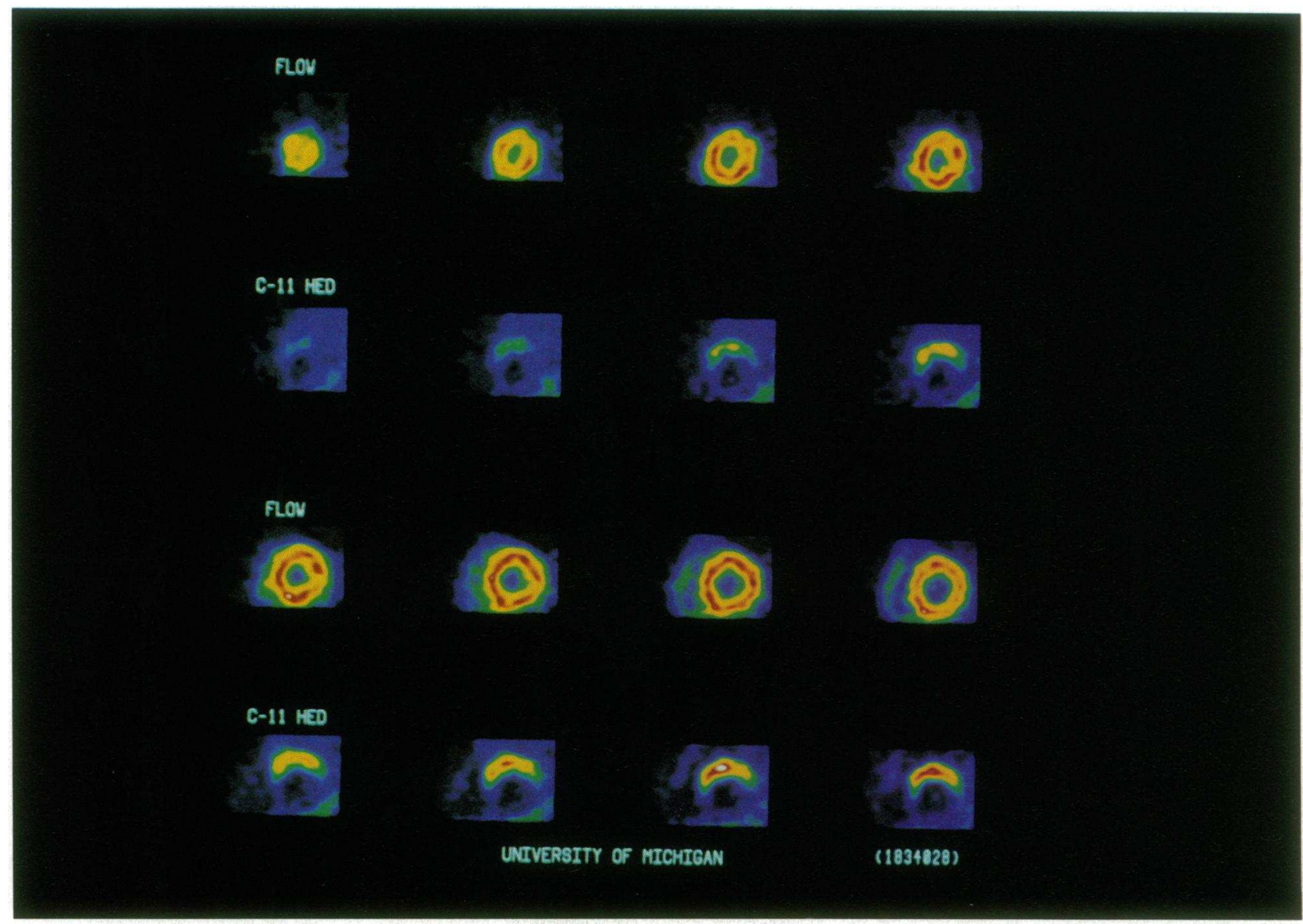

Figure 3. Eight short axis PET images obtained in one patient $55 \mathrm{mo}$ after cardiac transplantation. The circulation is identical as in Fig. 1. Rubidium-82 images above show homogeneous blood flow throughout the left ventricle. [ $\left.{ }^{11} \mathrm{C}\right]$ HED images below indicate tracer retention in the anterior aspects of the left ventricle increasing from mid left ventricle towards the base of the left ventricle (lower row). 
Table II. Scintigraphic Results

\begin{tabular}{lcccc}
\hline & Base & Mid ventricle & Apical & Total \\
\hline $\begin{array}{l}\text { Normals } \\
\quad n=5\end{array}$ & $16.6 \pm 2.3$ & $17.9 \pm 2.4$ & $15.1 \pm 2.6^{*}$ & $16.6 \pm 2.7$ \\
$\begin{array}{l}\text { Early transplant } \\
\quad n=5\end{array}$ & $4.9 \pm 1.8$ & $4.9 \pm 1.3$ & $4.1 \pm 0.8^{*}$ & $4.6 \pm 1.4^{\ddagger}$ \\
$\begin{array}{l}\text { Late transplant } \\
n=6\end{array}$ & $7.0 \pm 3.7^{\S}$ & $7.2 \pm 3.2^{\S}$ & $5.3 \pm 1.4$ & $6.5 \pm 2.9^{\ddagger}$ \\
\hline
\end{tabular}

${ }^{*} P \leq 0.05$ vs. basal and mid-ventricular segments. ${ }^{\ddagger} P<0.05$ vs. normals. ${ }^{8} P<0.05$ vs. early transplant.

averaged 16.6 and was homogeneous throughout the left ventricle in the normal patient population (Fig. 4).

In group I patients, a global myocardial [ $\left.{ }^{11} \mathrm{C}\right] \mathrm{HED}$ retention was only $28 \%$ of that found in the normal volunteers $(P$ $<0.001)$. The tracer retention was similar in the basal, mid, and apical segments of the left ventricle. The $\left[{ }^{11} \mathrm{C}\right] \mathrm{HED}$ retention differences between the anterior, lateral, and inferior septal segments of the left ventricle were not significant (Fig. 4).

Group II patients also demonstrated a globally decreased myocardial $\left[{ }^{11} \mathrm{C}\right] \mathrm{HED}$ retention as compared with the normal control population $(P<0.001)$ (Table II). However, the retention of the tracer was significantly higher in the basal segments as compared with apical segments of the left ventricle $(P$ $<0.01$ ) (Fig. $4 A$ ). Specifically, $\left[{ }^{11} \mathrm{C}\right]$ HED retention in the prox- imal anterior wall and septum was increased. In one patient the tracer retention was equal to normal values (Fig. $4 \mathrm{~B}$ ). The tracer retention in inferior and lateral segments averaged only $30-40 \%$. [ $\left.{ }^{11} \mathrm{C}\right]$ HED retention in the apical segments of group I and group II patients was not significantly different (Fig. $4 \mathrm{~A}$ ). The individual regional $\left[{ }^{11} \mathrm{C}\right] \mathrm{HED}$ retention data of group II patients are compared to the mean normal values in Fig. $4 B$ indicating considerable variability of regional tracer retention in this patient group.

Histological analysis. Microscopic examination of sections from the one patient who died 60 mo after cardiac transplantation revealed viable appearing nerve twigs in the blocks taken from the left ventricular apex as well as the base (Fig. 5, $A$ and $B$ ). Schwann cells and endoneural fibroblasts had a similar appearance in nerves from both of these locations. However, actual axons were demonstrable in the Holmes stain only in the sections taken from the basal aspect of the left ventricle and not in the apical portion (Fig. 5, $C$ and $D$ ). In the corresponding preparations stained for S-100, the basal myocardium of the left ventricle was seen to contain many more S-100 positive nerve fibers than the apical portion of the ventricle.

Clinical testing of autonomic nervous system. Table III summarizes the incidence of abnormal test results of the clinical evaluation of the cardiovascular autonomic nervous system in group I and group II patients. The evaluation revealed abnormal responses in all group I and group II patients. There was no significant difference between both groups in the test results evaluating heart rate or blood pressure responses.
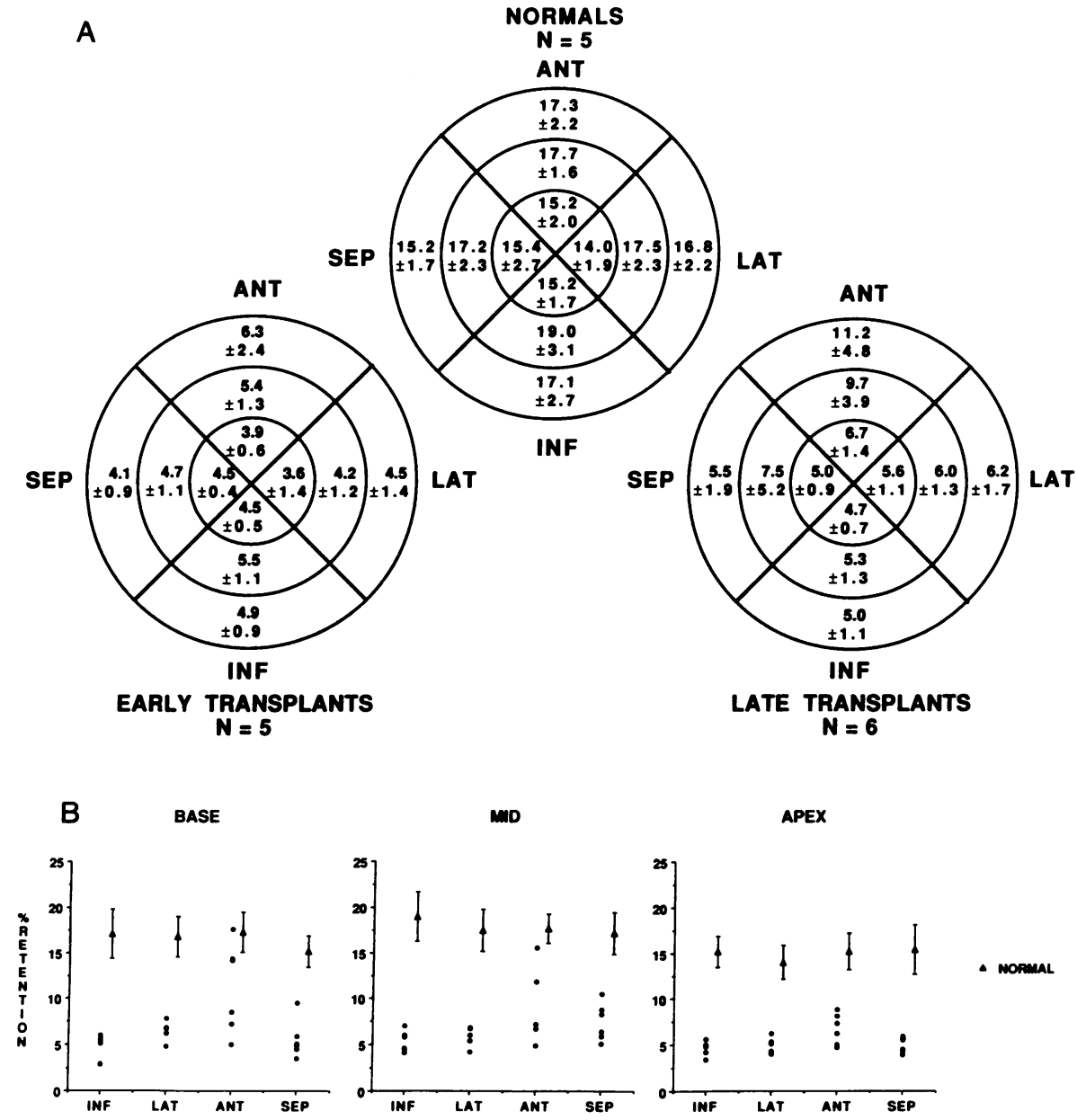

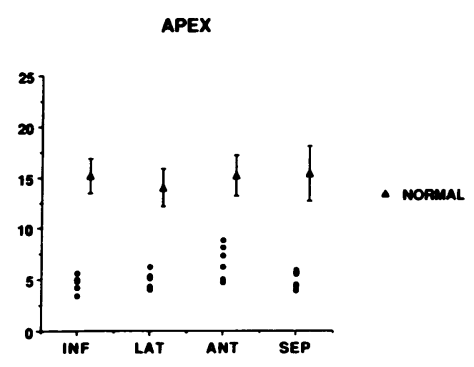

Figure 4. $(A)$ Polar map representation of regional $\left[{ }^{11} \mathrm{C}\right] \mathrm{HED}$ retention in all three groups. Regional apical retention of tracer is projected on the center of the map, while the most basal plane forms the center ring. Tracer retention is defined as regional tissue activity divided by the integral of arterial input function. $A N T$, anterior; $I N F$, inferior; $S E P$, septal; and $L A T$, lateral. $(B)$ Individual $\left[{ }^{11} \mathrm{C}\right] \mathrm{HED}$ retention data in group II patients (circles) as compared with mean values $\pm \mathrm{SD}$ in normal volunteers (triangles). 


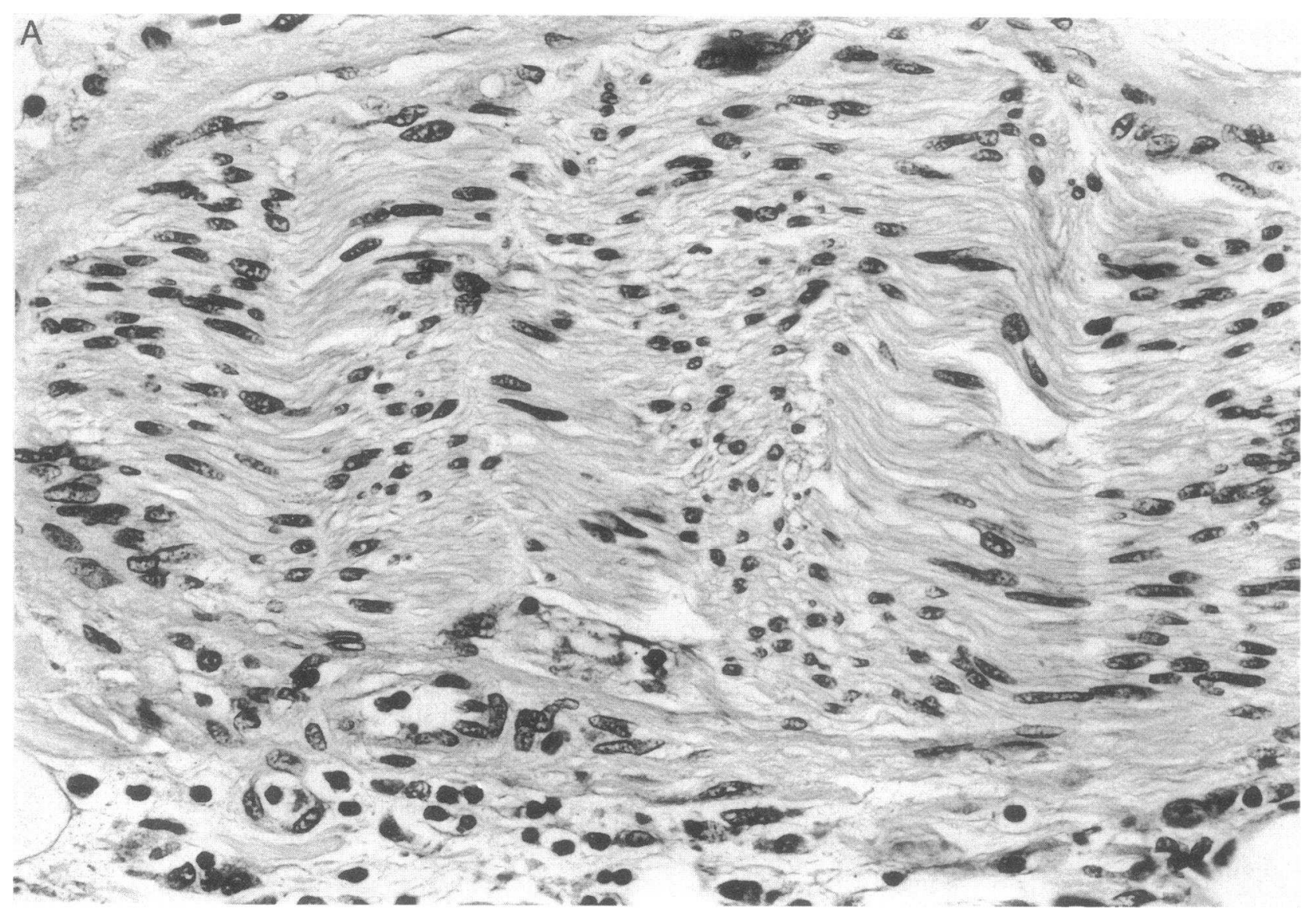

Figure 5. (A) Photomicrograph of nerve from basal portion of anterior left ventricle obtained in the patient shown in Fig. 4. Most of the nuclei are those of unremarkable Schwann cells and endoneurial fibroblasts. A few lymphocytes are evident at the lower border of the nerve (hematoxylin and cosin, $\times 470$ ). (B) Photomicrograph of nerves from apical portion of anterior left ventricle. As seen in this routine preparation, the nerves, although smaller, are not significantly different from that in $A$ (hematoxylin and cosin, $\times 470)$. $(C)$ Photomicrograph of nerve from basal portion of anterior left ventricle. The wavy black lines in this silver-stained preparation are axons (Holmes stain, $\times 470)$. $(D)$ Photomicrograph of nerve from apical portion of anterior left ventricle. Axons are not seen at this level (Holmes stain, $\times 470$ ).

\section{Discussion}

The results of this study indicate that myocardial $\left[{ }^{11} \mathrm{C}\right] \mathrm{HED}$ retention as a marker of neuronal catecholamine uptake and storage is homogeneously reduced early after cardiac transplantation. The quantitative assessment of the $\left[{ }^{11} \mathrm{C}\right] \mathrm{HED}$ retention revealed homogeneous reduction throughout the left ventricle to only $28 \%$ of control values. In contrast, patients with remote cardiac transplantation demonstrated increased retention of the tracer confined to the anterobasal and anteroseptal segments of the left ventricle suggesting regional presence of neuronal tissue. The quantitative evaluation revealed globally decreased $\left[{ }^{11} \mathrm{C}\right] \mathrm{HED}$ retention in patients with remote cardiac transplantation. However, there was a significant tracer retention gradient from the base to the apex of the left ventricle confirming the visual impression. Histologic examination in one patient revealed more axons (in a silver stain) and more intramyocardial S-100 positive fibers (in an immunoperoxidase stain) in the base as compared with the apex of the left ventricle. Although one cannot distinguish with these methods between axons of postganglionic parasympathetic nerves retained in the transplant and regenerated sympathetic axons that have reinnervated the heart, the observed difference in the two regions correlates with the scintigraphic results, and is suggestive for reinnervation which would be expected to proceed slowly from base to apex.

Methodologic considerations. [ $\left.{ }^{11} \mathrm{C}\right] \mathrm{HED}$ represents a new catecholamine analogue for PET $(16,26)$. This tracer mimics the neuronal uptake and storage of norepinephrine (15). In contrast to norepinephrine, the tracer is not metabolized in sympathetic nerve terminals by monoamine oxidase (27). Animal experiments in the rat and canine heart using pharmacological inhibition of neuronal uptake I mechanism (desimipramine) and vesicular storage (reserpine) demonstrated reduction of tracer retention by $>90 \%$ (26). These data indicate the high specificity of this tracer for neuronal binding sites. Following uptake and storage, the tracer is retained in tissue with a long biological half-life. Correlation of tissue $\left[{ }^{11} \mathrm{C}\right] \mathrm{HED}$ retention with tissue norepinephrine content in a canine model of regional cardiac denervation showed a close relationship of both measurements $(15,26)$.

The analysis of tissue [ $\left.{ }^{11} \mathrm{C}\right] \mathrm{HED}$ kinetics has been confined to the left ventricle only. This limitation is due to the spatial resolution of the imaging device used. State-of-the-art PET provides a spatial resolution $\sim 6-8 \mathrm{~mm}$. This resolution compares favorably with the left ventricle wall thickness $\sim 1.2 \mathrm{~cm}$ 


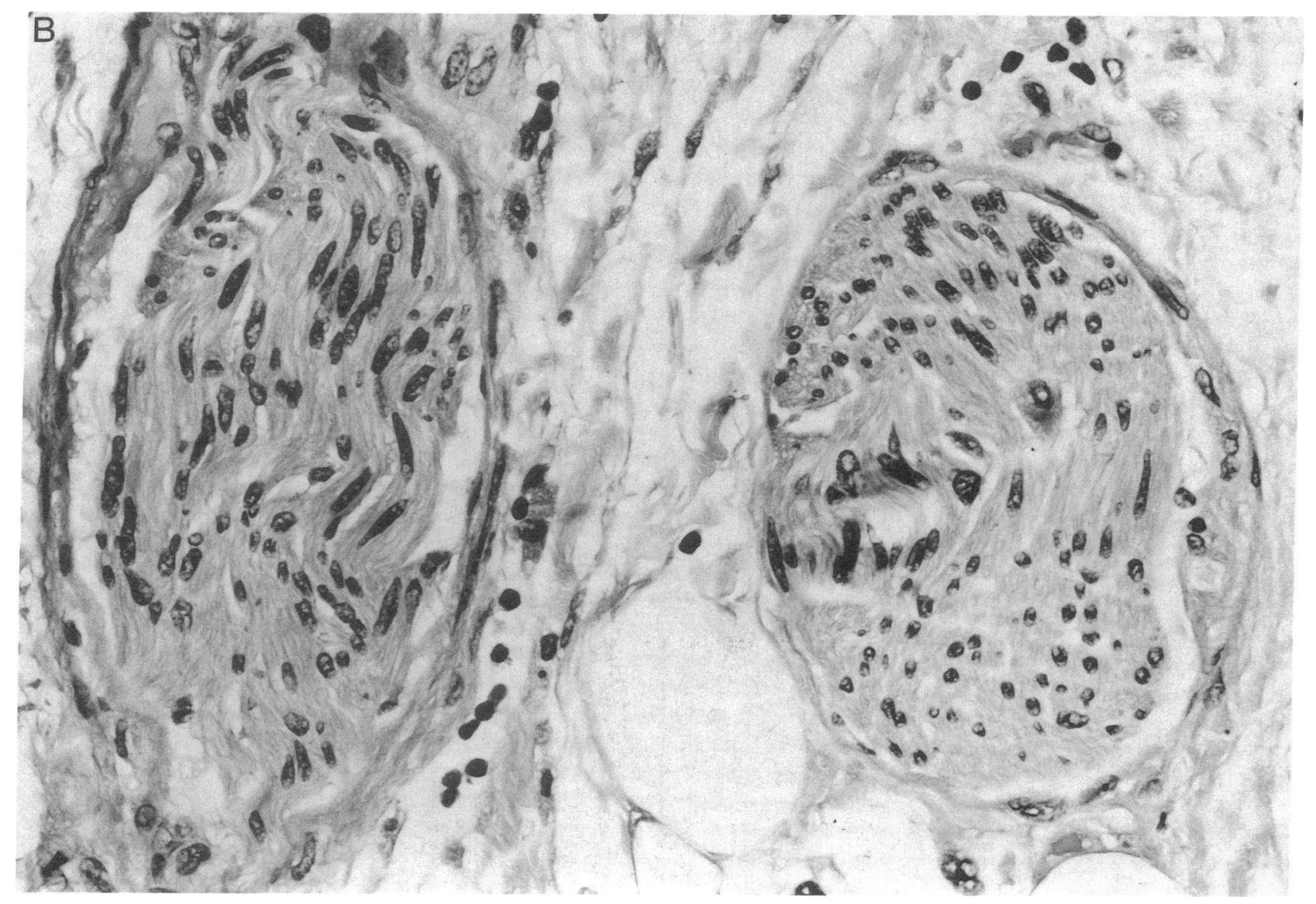

Figure 5 (Continued)

but is crude in comparison to the thickness of the left atrial wall as well as right ventricular wall $(3-6 \mathrm{~mm})$. Therefore, the retention of the tracer in these structures of the heart cannot be accurately determined (28). However, in vitro tissue counting in the animal model has shown that the ${ }^{11} \mathrm{C}$ activity per gram of tissue in the left atrium and right ventricle is comparable to that of the left ventricle (26). These findings are consistent with the known dense sympathetic innervation of the atria as well as the right ventricle (29). Because of these geometric limitations, we could not assess the possible reinnervation in the left or right atrium. The observed findings in the left ventricle suggest that the basal segments of the right ventricle may be reinnervated to the same extent as the basal segments of the left ventricle.

Data interpretation. This study provides the first direct evidence for catecholamine uptake and retention in the transplanted human heart. There is ongoing controversy over whether the human heart does demonstrate reinnervation ( 3 , $30-32$ ). A recent study indicated that patients with remote cardiac transplantation demonstrate increased norepinephrine spillover following the injection of tyramine, suggesting myocardial release of norepinephrine from nerve terminals (33). This indirect evidence of reinnervation agrees with our scintigraphic findings of tracer retention in the transplanted heart.

Reinnervation has been well established in various animal models of cardiac transplantation including primates $(12,14$, 34-37). Evidence for reinnervation has been confirmed not only after autotransplantation but also in allografted animals given immunosuppressive therapy (35). Peiss and co-workers demonstrated that vagal reinnervation occurs as early as 4 wk and sympathetic reinnervation as early as $10 \mathrm{wk}$ after autotransplantation in the canine model (38). The same authors reported that the functional responses to electro-activation of the nerves were similar to those in normal dogs 3 yr after transplantation (38). Histochemical evaluation of canine cardiac transplants demonstrated regeneration of adrenergic fibers $1 \mathrm{yr}$ after surgery (13). Kaye et al. have reported that reinnervation occurs as early as 3 mo in the canine model using stimulation of the stellate ganglion and measurements of regional myocardial function. Serial stimulation studies suggested a regional pattern of reinnervation (29). The left ventricular base responded with a greater degree to the stimulation than the more distal aspects of the left ventricle. Assessment of tissue norepinephrine levels in animals following cardiac transplant demonstrated higher values in the left atrium, right atrium, and left ventricular base as compared with the right and left ventricular apex. However, the overall norepinephrine tissue content was lower than in normal control animals $(29,38)$. The authors concluded that evidence of autonomic reinnervation of the surgically denervated canine heart progresses from the base to apex and is functionally complete at $\sim 9$ mo after denervation. The recovery of neuronal function paralleled the return of measurable quantities of myocardial norepinephrine and decrease of hypersensitivity to infused norepinephrine (29).

Similar evidence for the reinnervation of transplants in humans has not been reported. Rowan and Regitz found no evidence for reinnervation in endomyocardial biopsies of heart 


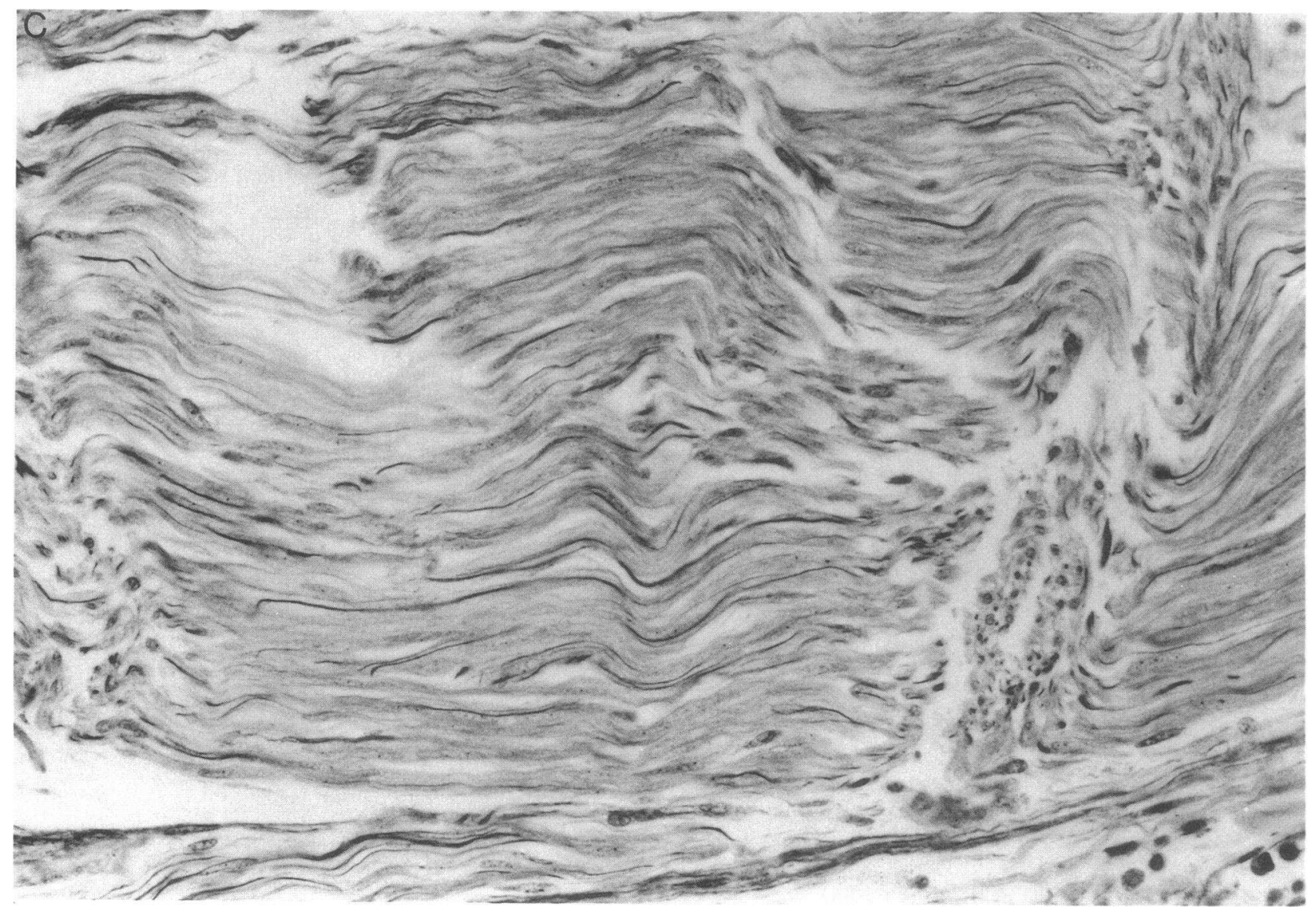

Figure 5 (Continued)

transplant survivors $(11,32)$. However, such biopsies generally represent the apical septum, an area which would likely be reinnervated very late if at all. In contrast, Bristow et al. recently reported norepinephrine levels $>50 \mathrm{ng} / \mathrm{g}$ wet tissue in about a third of tissue samples of transplant recipients undergoing retransplantation suggesting reinnervation (31). Clinical evaluation of the autonomic nervous system by clinical tests performed in this study did not reveal evidence for functional reinnervation. However, the techniques employed are relatively crude and lack sensitivity, especially for regional reinnervation (23). A recent report employing analysis of heart rate variability using spectral analysis revealed increased heart rate variability late after transplantation suggesting atrial reinnervation (39). Such sophisticated analysis was not employed in this study.

The scintigraphic results agree closely with the data observed in the animal studies. The basal segments of the anterior and anterior-septal wall of the left ventricle appeared to retain the tracer to a larger degree than the more distal segments of the left ventricle indicating regional storage capacity for catecholamines. The quantification of $\left[{ }^{11} \mathrm{C}\right] \mathrm{HED}$ kinetics indicated considerable variability among patients, but the overall storage capacity remains reduced as compared to normal myocardium. Again, these data confirm the direct measurement of norepinephrine tissue content in experimentally transplanted hearts (29). However, in contrast to the animal data, the time course of reinnervation in the human heart appears to be prolonged.
Longitudinal studies in the same patient population are required to define the time course and full extent of reinnervation in the human heart.

The clinical significance of partial reinnervation of the human transplanted heart is unclear. Clinical studies have suggested that the heart rate response to exercise tends to normalize late after transplantation. The lack of clinical evidence for autonomic reflex control of the transplanted heart indicates absence of physiologic meaningful reinnervation. However, independent of the integrity of the reflex control, the presence of neuronal structures that sequester and possibly release norepinephrine may affect regional sympathetic tone. The amine uptake mechanism of the sympathetic nerve terminal plays an important role in regulation of the extraneuronal norepinephrine concentration. Heterogeneity of norepinephrine removal or release may affect regional electrophysiologic properties and/or vascular reactivity. Heterogeneous sympathetic tone has been linked to increased incidence of arrhythmias, especially in the setting of ischemia. Further studies are required to define the physiologic significance of partial reinnervation of the transplanted human heart.

Conclusion. Neuronal imaging with $\left[{ }^{11} \mathrm{C}\right] \mathrm{HED}$ allows the noninvasive delineation of sympathetic nerve terminals. The study demonstrated the feasibility of this novel imaging approach to delineate cardiac denervation following cardiac transplantation. In contrast to other techniques, this imaging method allows regional definition of neuronal uptake and stor- 


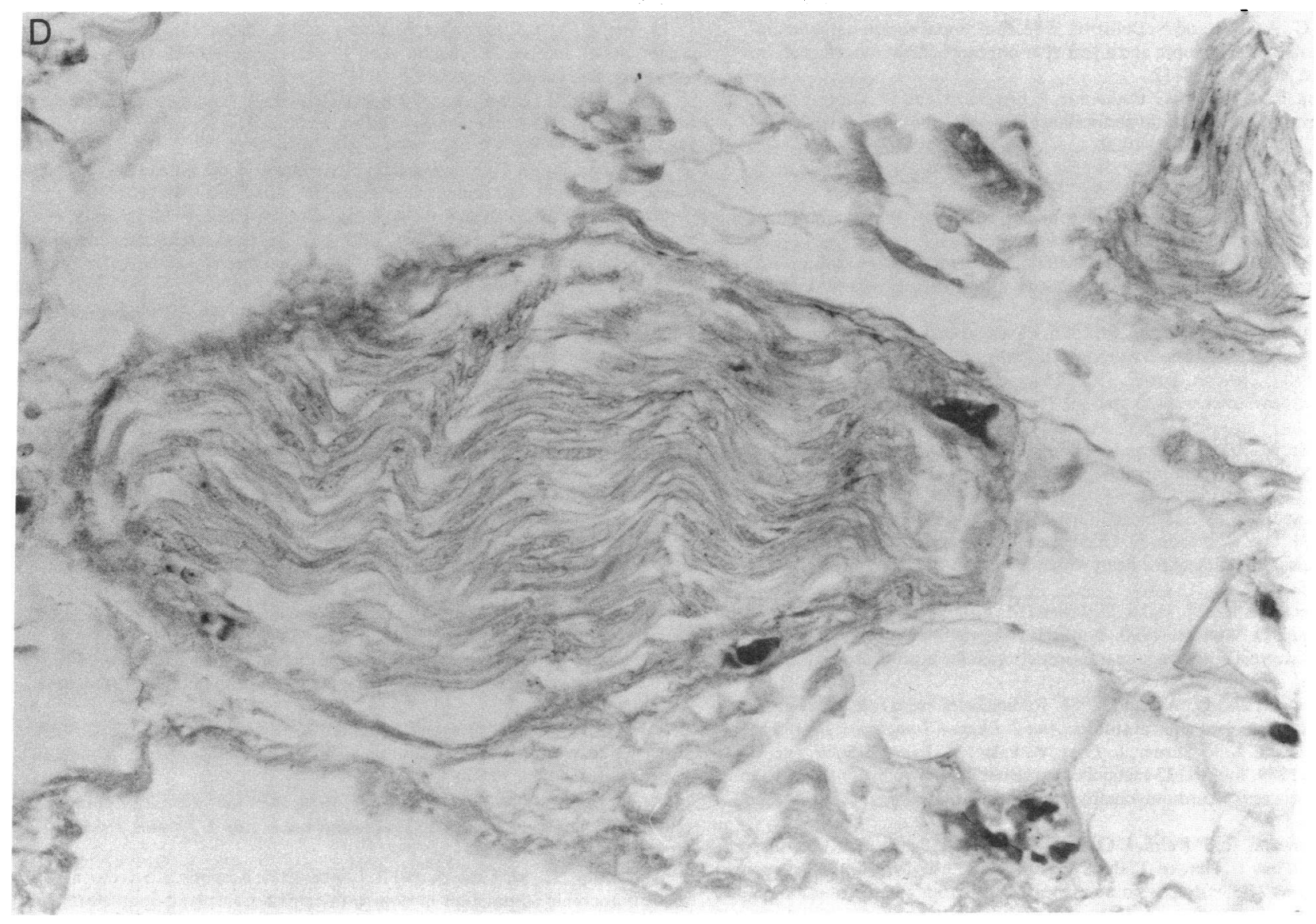

Figure 5 (Continued)

age of the norepinephrine analogue $\left[{ }^{11} \mathrm{C}\right] \mathrm{HED}$. Using this approach we could demonstrate for the first time the presence of neuronal catecholamine uptake in the proximal aspects of the human transplant. This pattern occurred only in patients with remote cardiac transplantation indicating the presence of neuronal structures that may reflect reinnervation. The functional significance of these findings is not defined and requires future studies including electrophysiologic evaluation of regional autonomic function.

Table III. Clinical Evaluation of Cardiovascular Autonomic Reflexes

\begin{tabular}{lcc}
\hline & $\begin{array}{c}\text { Early transplant } \\
\text { abnormal response }\end{array}$ & $\begin{array}{c}\text { Late transplant } \\
\text { abnormal response }\end{array}$ \\
\hline $\begin{array}{l}\text { Postural systolic hypotension* } \\
\text { Heart rate variation* } \\
\quad \text { (deep breathing) }\end{array}$ & $0 / 3$ & $1 / 4$ \\
$\begin{array}{l}\text { Heart rate variation* } \\
\text { (Valsalva) }\end{array}$ & $3 / 3$ & $4 / 4$ \\
$\begin{array}{l}\text { Heart rate variation* } \\
\text { (standing) }\end{array}$ & $3 / 3$ & $4 / 4$ \\
$\begin{array}{c}\text { Diastolic pressure change with } \\
\text { handgrip* }\end{array}$ & $3 / 3$ & $4 / 4$ \\
\hline
\end{tabular}

*(23).

\section{Acknowledgments}

We would like to thank the Cyclotron staff at the University of Michigan for producing carbon-11 necessary for the labeling of $\left[{ }^{11} \mathrm{C}\right] \mathrm{HED}$. The rubidium-82 generators were generously supplied by Squibb Diagnostics. We would like to thank Jill Rothley, Leslie Shaw, Annette Bentley, and Vince McCormick for the excellent technical assistance in performing these studies. We also thank Mrs. Vi Rhodes and Mrs. Tina Bennett for preparation of the manuscript.

This work was performed during the tenure of an established investigatorship from the American Heart Association (M. Schwaiger), and supported by the National Institutes of Health, Lung, Blood, and Heart Institute (RO1 HL-41047-01 and RO1 HL-27555-06).

\section{References}

1. Fragomeni, L., and M. Kaye. 1988. The registry of the International Society for Heart Transplantation: fifth official report. J. Heart Transplant. 7:249-253.

2. Stevenson, L., K. Sietsema, J. Tillisch, V. Lem, J. Walden, J. Kobashigawa, and J. Moriguchi. 1990. Exercise capacity for survivors of cardiac transplantation or sustained medical therapy for stable heart failure. Circulation. 81:78-85.

3. Kavanagh, T. M. Yacoub, D. Mertens, J. Kennedy, R. Campbell, and P. Sawyer. 1988. Cardiorespiratory responses to exercise training after orthotopic cardiac transplantation. Circulation. 77:162-171.

4. Banner, N., N. Patel, A. Cox, H. Patton, D. Lachno, and M. Yacoub. 1989. Altered sympathoadrenal response to dynamic exercise in cardiac transplant recipients. Cardiovasc. Res. 23:965-972.

5. Donald, D., and J. Shepherd. 1964. Initial cardiovascular adjustment to exercise in dogs with chronic cardiac denervation. Am. J. Physiol. 207:13251329.

6. Schroeder, J. 1979. Hemodynamic performance of the human transplanted heart. Transplant. Proc. 11:304-308. 
7. Niset, G., A. Piret, and N. Delbarre. 1988. Functional non-invasive cardiorespiratory evaluation a month and a year after orthotopic heart transplantation. Ann. Cardiol. Angeiol. 37:9-12.

8. Guyton, R., J. Bianco, G. Ostheimer, E. Shanahan, and W. Daggett. 1972. Adrenergic control of ventricular performance in normal and cardiac-denervated dogs. Am. J. Physiol. 223:1021-1028.

9. Beck, W., C. Barnard, and V. Schrire. 1969. Heart rate after cardiac transplantation. Circulation. 40:437-445.

10. Dong, E., Jr., E. Hurley, R. Lower, and N. Shumway. 1964. Performance of the heart two years after autotransplantation. Surgery (St. Louis). 56:270-273.

11. Rowan, R., and M. Billingham. 1988. Myocardial innervation in long term heart transplant survivors: a quantitative ultrastructural survey. $J$. Heart Transplant. 7:448-452.

12. Ebert, P., and D. Sabiston, Jr. 1970. Pharmacologic quantitation of cardiac sympathetic reinnervation. Surgery (St. Louis). 68:123-127.

13. Norvell, J., and R. Lower. 1973. Degeneration and regeneration of the nerves of the heart after transplantation. Transplantation (Baltimore). 15:337344.

14. Kondo, Y., J. Matheny, and J. Hardy. 1972. Autonomic reinnervation of cardiac transplants: further observations in dogs and rhesus monkeys. Ann. Surg. 176:24-28.

15. Wieland, D., K. Rosenspire, G. Hutchins, M. VanDort, J. Rothley, S. Mislankar, H. Lee, C. Massin, D. Gildersleeve, P. Sherman, and M. Schwaiger. 1990. Neuronal mapping of the heart with 6-[F-18]Fluorometaraminol. J. Med. Chem. 33:956-964.

16. Rosenspire, K., M. Haka, D. Jewett, M. VanDort, D. Gildersleeve, M. Schwaiger, and D. Wieland. 1990. Synthesis and preliminary evaluation of [C11]meta-hydroxyephedrine: a false transmitter agent for heart neuronal imaging. J. Nucl. Med. 31:163-167.

17. Sisson, J., and D. Wieland. 1986. Radiolabeled meta-iodobenzylguanidine: pharmacology and clinical studies. Am. J. Physiol. Imaging. 1:96-103.

18. Glowniak, J., F. Turner, L. Gray, R. Palac, M. Lagunas-Solar, and W. Woodward. 1989. Iodine-123 metaiodobenzylguanidine imaging of the heart in idiopathic congestive cardiomyopathy and cardiac transplants. J. Nucl. Med. 30:1182-1191.

19. Henderson, E., J. Kahn, J. Corbett, D. Jansen, J. Pippin, P. Kulkarni, V. Ugolini, M. Akers, C. Hansen, L. Buja, R. Parkey, and J. Willerson. 1988. Abnormal I-123 metaiodobenzylguanidine myocardial washout and distribution may reflect myocardial adrenergic derangement in patients with congestive cardiomyopathy. Circulation. 78:1192-1199.

20. Schwaiger, M. V. Kalff, K. Rosenspire, M. Haka, E. Molina, G. Hutchins, M. Deeb, E. Wolfe, Jr., and D. Wieland. 1990. Noninvasive evaluation of the sympathetic nervous system in the human heart by PET. Circulation. 82:457464.

21. Hutchins, G., M. Schwaiger, M. Haka, K. Rosenspire, and D. Wieland. 1989. Compartmental analysis of the behavior of catecholamine analogs in myocardial tissue. J. Nucl. Med. 30:735.

22. Hutchins, G., M. Schwaiger, K. Rosenspire, and D. Wieland. 1990. Evaluation of sympathetic innervation in the human heart using [C-11] hydroxyephedrine: a distribution volume approach. J. Nucl. Med. 31:725. (Abstr.)
23. Ewing, D., N. Christopher, R. Young, and B. Clarke. 1985. The values of cardiovascular autonomic function tests: 10 years experience in diabetes. Diabetes Care. 8:491-498.

24. Luna, L. G., editor. 1968. Manual of Histologic Staining Methods of the Armed Forces Institute of Pathology. 3rd ed. McGraw-Hill Inc., New York. 196198.

25. Vracko, R., D. Thorning, and R. Frederiskson. 1990. Fate of nerve fibers in necrotic, healing, and healed rat myocardium. Lab. Invest. 63:490-500.

26. Wieland, D., G. Hutchins, K. Rosenspire, M. Haka, P. Sherman, T. Pisani, N. Nguyen, and M. Schwaiger. 1989. [C11]Hydroxyephedriene (HED): a high specific activity alternative to 6-[F-18]fluorometaraminol (FMR) for heart neuronal imaging. J. Nucl. Med. 30:767.

27. Fuller, R., H. Snoddy, K. Perry, J. Bernstein, and P. Murphy. 1981. Formation of alpha-methylnorepinephrine as a metabolite of metaraminol in guinea pigs. Biochem. Pharmacol. 30:2831-2836.

28. Hoffman, E., and M. Phelps. 1986. Positron emission tomography: principles and quantitation. In Positron Emission Tomography and Autoradiography: Principles and Applications for the Brain and Heart. M. Phelps, J. Mazziotta, and H. Schelbert, editors. Raven Press, Ltd., New York. 237-286.

29. Kaye, M. Denervation and Reinnervation of the Heart. 1977. In Neural Regulation of the Heart. W. Randall, editor. Oxford University Press, New York. 278-306.

30. Pope, S., E. Stinson, G. Daughters, J. Schroeder, N. Ingels, and E. Alderman. 1980. Exercise response of the denervated heart in long term cardiac transplant recipients. Am. J. Cardiol. 46:213-218.

31. Bristow, M. 1990. The surgically denervated, transplanted human heart. Circulation. 82:658-660.

32. Regitz, V., C. Bossaller, R. Strasser, S. Schüler, R. Hetzer, and E. Fleck. 1990. Myocardial catecholamine content after heart transplantation. Circulation. 82:620-623.

33. Wilson, R., B. Christensen, A. Simon, M.-T. Olivari, and C. White. 1990 Evidence for sympathetic reinnervation after cardiac transplantation in humans. J. Am. Coll. Cardiol. 15:85a. (Abstr.)

34. Kaye, M., D. Wells, and G. Tyce. 1979. Nerve growth factor enhanced reinnervation of surgically denervated canine heart. Am. J. Physiol. 236:H624H628.

35. Kontos, H., M. Thames, and R. Lower. 1970. Responses to electrical and reflex autonomic stimulation in dogs with cardiac transplantation before and after reinnervation. J. Thorac. Cardiovasc. Surg. 59:382-392.

36. Seki, S., and G. Danielson. 1971. Characteristics of cardiac reinnervation in growing calves. J. Thorac. Cardiovasc. Surg. 62:602-607.

37. Willman, V., T. Cooper, and C. Hanlon. 1964. Return of neural responses after autotransplantation of the heart. Am. J. Physiol. 207:187-189.

38. Peiss, C., T. Cooper, V. Willman, and W. Randall. 1966. Circulatory responses to electrical and reflex activation of the nervous system after cardiac denervation. Circ. Res. 19:153-166.

39. Mohanty, P., J. Sowers, M. Thames, F. Beck, A. Kawaguchi, and R. Lower. 1986. Myocardial norepinephrine, epinephrine and dopamine concentration after cardiac autotransplantation in dogs. J. Am. Coll. Cardiol. 7:419-424. 